\title{
Pengenalan Traffic Light Pada Robot Mobil Duckietown
}

\author{
Erwin Sanjaya Loeminto \\ Program Studi Teknik Elektro \\ Universitas Kristen Petra \\ erwin.loeminto@gmail.com
}

\author{
Handry Khoswanto \\ Program Studi Teknik Elektro \\ Universitas Kristen Petra \\ handry@petra.ac.id
}

\author{
Resmana Lim \\ Program Studi Teknik Elektro \\ Universitas Kristen Petra \\ resmana@petra.ac.id
}

\begin{abstract}
Abstrak - Duckietown adalah sebuah proyek penelitian yang berfokus pada self-driving vehicle dan high-level autonomy. Penelitian ini bertujuan untuk mengendalikan Duckiebot saat menemukan adanya traffic light. Duckiebot terdiri dari Raspberry $\mathrm{Pi} 3$ sebagai controller, fisheye lens camera sebagai sensor, dan motor DC sebagai aktuator. Raspberry $\mathrm{Pi} 3$ menerima dan memproses gambar yang didapat oleh kamera menggunakan library OpenCV. Dalam pemrosesan gambar, pertama adalah penentuan lokasi traffic light. Kemudian pengambilan range warna traffic light yang akan diproses untuk menghasilkan aksi kontrol aktuator agar berjalan atau berhenti. Aksi kontrol aktuator dilakukan dengan menggunakan Robot Operating System (ROS). Pengujian dilakukan dengan cara melihat hasil deteksi, menjalankan mode lane following, mengubah-ubah pencahayaan, dan memberi gangguan berupa spanduk yang sewarna. Berdasarkan hasil pengujian, kamera dapat digunakan sebagai sensor Duckiebot untuk mengenali traffic light, tapi kamera sangat sensitif terhadap perbedaan pencahayaan sehingga untuk kondisi terang, gelap, dan backlight akan memiliki hasil yang berbeda.

Kata Kunci: Duckiebot, Raspberry Pi 3, Robot Operating System (ROS), Traffic Light.
\end{abstract}

\section{PENDAHULUAN}

Duckietown adalah sebuah proyek penelitian yang berfokus pada self-driving vehicle dan high-level autonomy. Proyek ini dimulai pada tahun 2016 di MIT yang kemudian menjadi proyek internasional pada tahun 2017. Platform yang digunakan terdiri dari Duckiebot sebagai robot otonom sederhana, dan Duckietown sebagai infrastruktur tempat Duckiebot menavigasi [1].

Duckiebot adalah robot otonom sederhana yang hanya menggunakan sensor sebuah kamera. Pada pertengahan tahun 2017, Program Studi Teknik Elektro, Universitas Kristen Petra turut bekerja sama dengan National Chiao Tung University, Taiwan dalam pengembangan proyek Duckietown di Indonesia. Pengembangan Duckiebot sangatlah luas, salah satu yang akan di bahas yaitu pengenalan Duckiebot terhadap traffic light.
Traffic light adalah lampu yang digunakan untuk mengatur kelancaran lalu lintas di suatu persimpangan jalan dengan cara memberi kesempatan pengguna jalan lain dari masing-masing arah untuk berjalan secara bergantian [2]. Berdasarkan penelitian mengenai pendeteksian traffic light untuk kendaraan otonom, algoritma berbasis kamera untuk deteksi traffic light secara real-time sudah dapat dilakukan dengan tepat. Percobaan menunjukkan algoritma yang dirancang untuk kendaraan otonom dapat bekerja baik dalam mendeteksi traffic light secara akurat [3].

Tentu pengenalan traffic light juga diperlukan Duckiebot agar dapat berlalu lintas di persimpangan terhadap Duckiebot lainnya. Oleh karena itu, pengenalan traffic light pada Duckiebot dapat dilakukan sekaligus diperlukan untuk pengembangan proyek Duckietown ini.

\section{PERENCANAAN SISTEM}

\section{A. Desain Sistem Duckiebot}

Duckiebot menggunakan Raspberry Pi 3 sebagai controller dengan sebuah kamera fisheye sebagai sensor yang menangkap gambar-gambar yang kemudian diproses oleh controller. Hasil pemrosesan gambar kemudian difungsikan sebagai pengambil keputusan geraknya motor yang di-drive oleh stepper motor HAT. Gambar 1 adalah desain sistem Duckiebot.

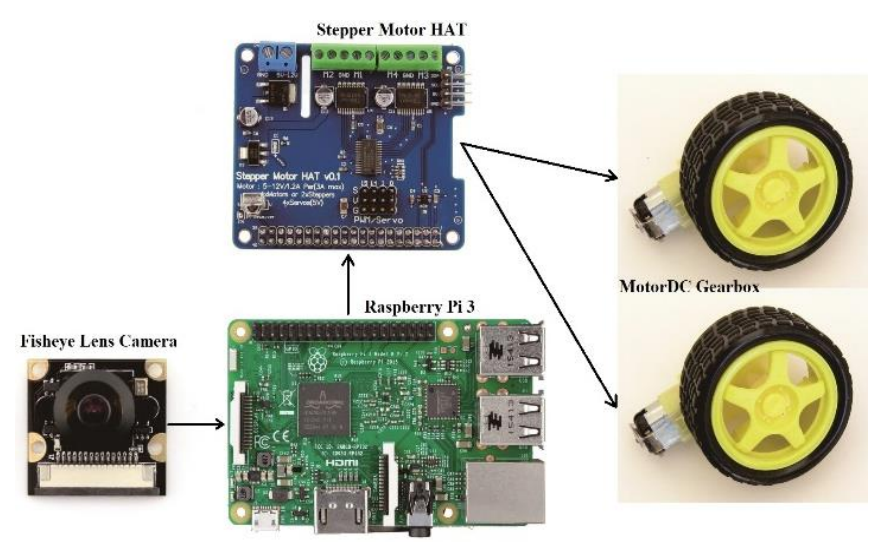

Gambar 1. Desain Sistem. 
Hasil perakitan robot Duckiebot terdapat pada Gambar 2.

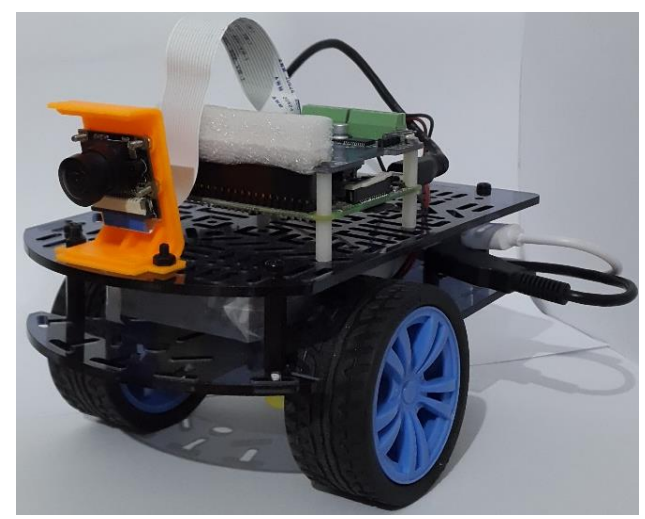

Gambar 2. Duckiebot Hardware.

B. Arena Duckietown

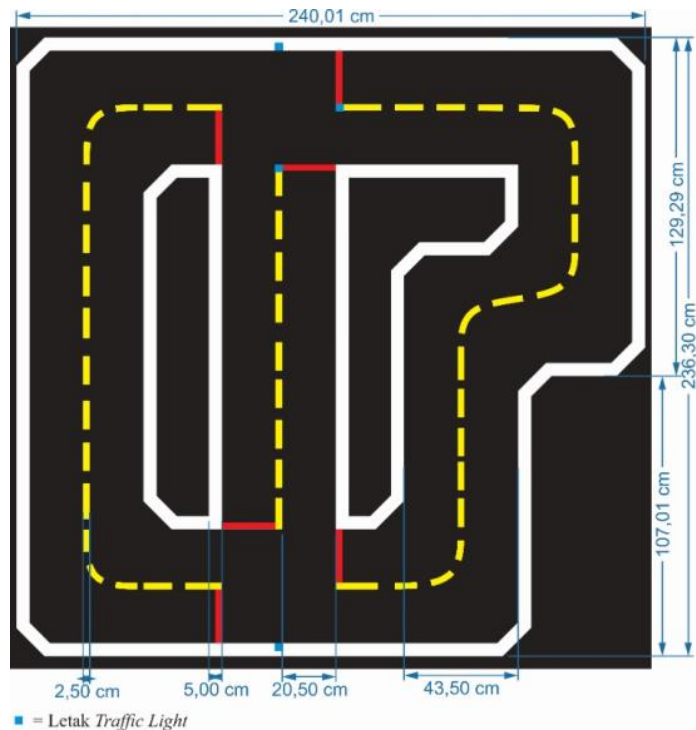

Gambar 3. Desain Arena Duckietown.

Seperti terlihat pada Gambar 3, arena terdapat persimpangan yang bertujuan untuk memanfaatkan lampu lalu lintas. Ukuran arena memiliki panjang $240 \mathrm{~cm}$ dan lebar $240 \mathrm{~cm}$. Setiap lajur memiliki lebar $20,5 \mathrm{~cm}$, lebar garis tepi $5 \mathrm{~cm}$ berwarna putih, dan lebar garis putus-putus pemisah lajur $2,5 \mathrm{~cm}$ berwarna kuning. Peletakan traffic light berada disebelah kanan lajur, dan di seberang depan garis stop line (garis merah) agar kamera masih dapat mendeteksi traffic light saat Duckiebot berada di dekat garis stop line.

\section{Proses Deteksi Traffic Light}

Dalam mendeteksi traffic light, Duckiebot memanfaatkan stop line yang telah tersedia oleh pengembang Duckietown. Pada saat mode lane following dijalankan, Duckiebot berjalan mengikuti lajurnya hingga mendeteksi garis stop line (garis merah). Duckiebot akan berhenti terlebih dahulu tepat pada sebelum garis stop line, kemudian kamera membaca warna traffic light. Saat Duckiebot mendeteksi merah, maka Duckiebot tetap berhenti. Sedangkan saat mendeteksi hijau, maka Duckiebot kembali berjalan dengan mode lane following.

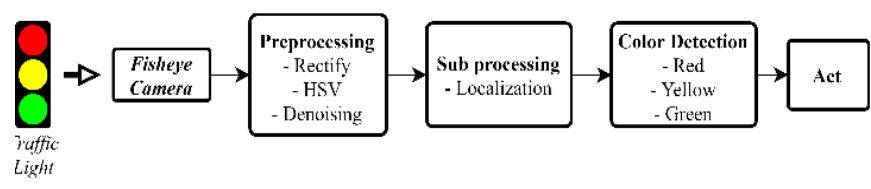

Gambar 4. Blok Diagram Pengendali Duckiebot terhadap Traffic Light.

Pada Gambar 4, sistem berjalan secara berulang, dimana ketika Duckiebot dijalankan maka proses preprocessing hingga act akan berjalan secara berulang. Saat proses pembacaan traffic light kamera menangkap gambar yang ada di depannya, kemudian gambar yang sebelumnya cembung akibat lensa fisheye kemudian di-rectify menjadi sebuah gambar yang datar. Setelah didapatkan gambar yang datar, kemudian diproses menjadi gambar HSV untuk memperjelas warna-warna yang dibutuhkan. Tentu banyak noise pada gambar yang didapat, sehingga diperlukan proses denoising untuk mengurangi noise pada gambar yang didapat.

Localization dilakukan untuk membaca traffic light pada suatu posisi tertentu. Hal ini diperlukan agar tidak setiap warna lampu merah, kuning, dan hijau dianggap sebuah traffic light dan tentunya setiap persimpangan pasti memiliki peletakan traffic light yang kurang lebih sama posisinya. Kemudian color detection membaca warna traffic light dan melakukan tindakan yang harus dilakukan.

\section{PENGUJIAN SISTEM DAN ANALISA}

A. Pengujian Pendeteksian Duckiebot terhadap Traffic Light

Pengujian pendeteksian traffic light bertujuan untuk mengetahui kesusaian range warna yang telah diatur. Gambar 5 menunjukkan hasil pengujian tiap warna dari traffic light yang terdeteksi berurutan dari merah, kuning, dan hijau.

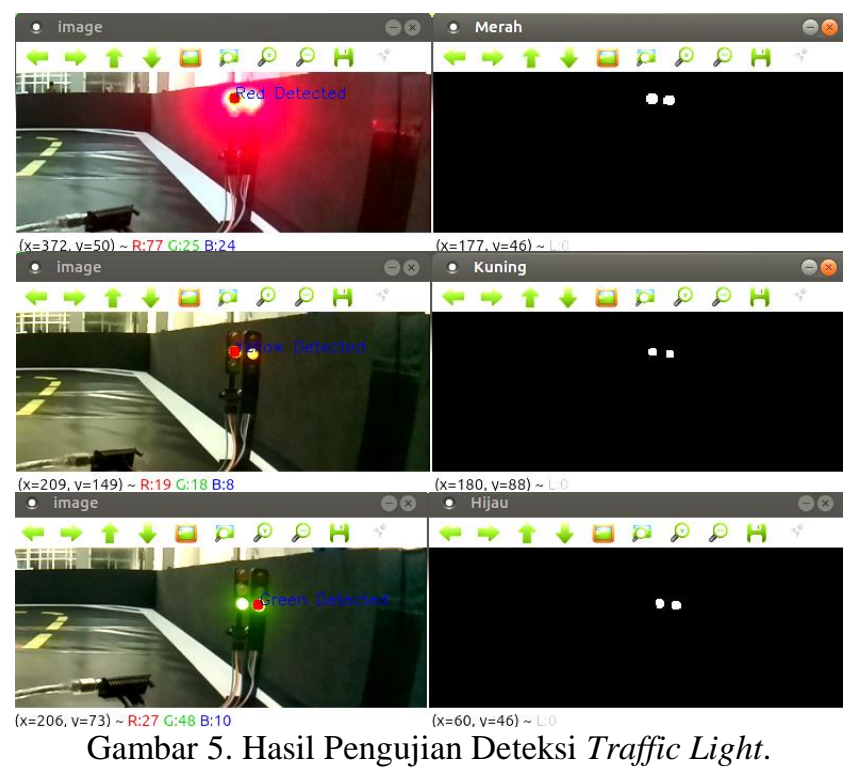


B. Pengujian Tindakan Duckiebot terhadap Traffic Light

Pengujian tindakan Duckiebot bertujuan untuk mengetahui tindakan Duckiebot saat mendeteksi traffic light. Pada Gambar 6 menggambarkan posisi pengujian yang telah dilakukan.

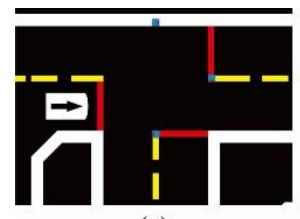

(a)

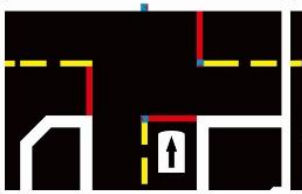

(b)

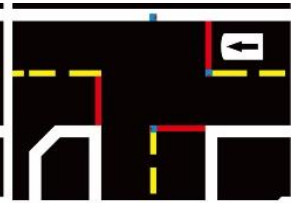

(c)
Gambar 6. Posisi Pengujian Tindakan Duckiebot terhadap Traffic Light.

Dari posisi pengujian pada Gambar 6 yang telah dilakukan sebanyak 5 kali tiap posisi, maka didapat data sebagai berikut:

Tabel 1. Pengujian Tindakan Duckiebot Posisi (a).

\begin{aligned} \multicolumn{1}{c}{ Pengujian ke } & Hasil Pengujian \\ \hline 1 & Berhasil \\ \hline 2 & Gagal \\ \hline 3 & Berhasil \\ \hline 4 & Berhasil \\ \hline 5 & Gagal \end{aligned}

Tabel 2. Pengujian Tindakan Duckiebot Posisi (b).

\begin{aligned} & \hline \multicolumn{1}{c}{ Pengujian ke } Hasil Pengujian \\ & \hline 1 Gagal \\ & \hline 2 Gagal \\ & \hline 3 Gagal \\ & \hline 4 Gagal \\ & \hline 5 Gagal \\ & \hline\end{aligned}

Tabel 3. Pengujian Tindakan Duckiebot Posisi (c).

\begin{aligned} & \hline \multicolumn{1}{c}{ Pengujian ke } Hasil Pengujian \\ & \hline 1 Gagal \\ & \hline 2 Berhasil \\ & \hline 3 Berhasil \\ & \hline 4 Berhasil \\ & \hline 5 Berhasil \\ & \hline\end{aligned}

Hasil pengujian pada posisi (b) tidak dapat dilakukan karena tidak ada garis lajur yang terdeteksi oleh kamera. Saat Duckiebot membaca traffic light berwarna hijau Duckiebot tidak mendeteksi lajur yang harus diikutinya, hal ini terbukti pada Gambar 7.
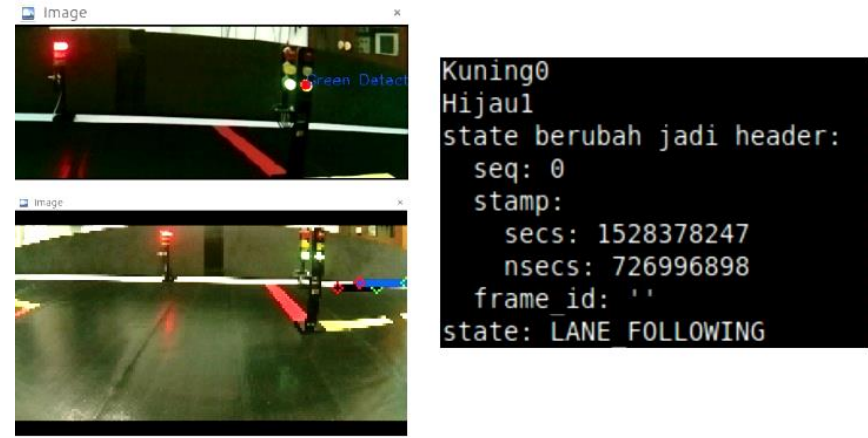

Gambar 7. Screenshot Rviz dan Terminal Duckiebot.

C. Pengujian Dua Duckiebot Saat Berpapasan dan Beriringan

Pengujian dua Duckiebot dilakukan untuk mengetahui bagaimana tindakan Duckiebot ketika dikondisikan seperti keadaan nyata yang tidak hanya satu kendaraan saja.

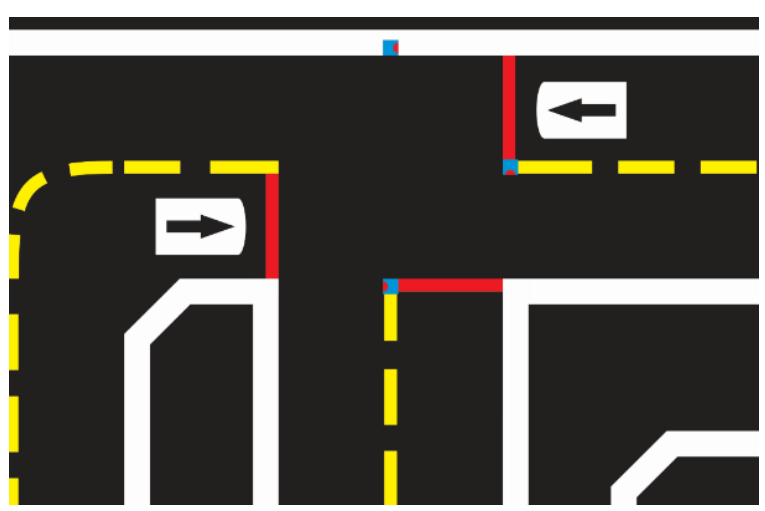

Gambar 8. Posisi Pengujian Dua Duckiebot Berpapasan.

Hasil pengujian secara berpapasan Duckiebot dapat mengikuti traffic light dengan baik sama halnya saat pengujian tindakan Duckiebot terhadap traffic light.

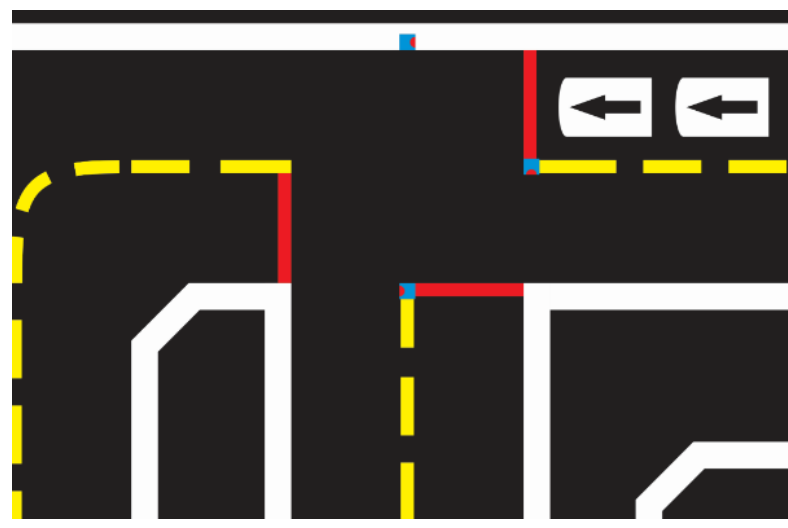

Gambar 9. Posisi Pengujian Dua Duckiebot Beriringan.

Hasil pengujian secara beriringan tidak dapat dilakukan karena pemrograman Duckiebot yang dilakukan tidak membuat Duckiebot mendeteksi sesama Duckiebot. 
D. Pengujian Dua Duckiebot saat Berpapasan dan Beriringan

Pengujian bertujuan untuk mengetahui sensitivitas kamera terhadap perbedaan cahaya.

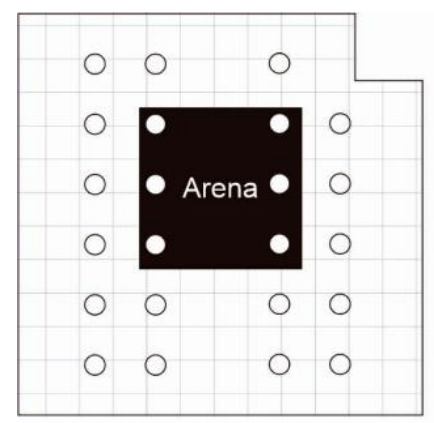

Pencahayaan Awal (LED)

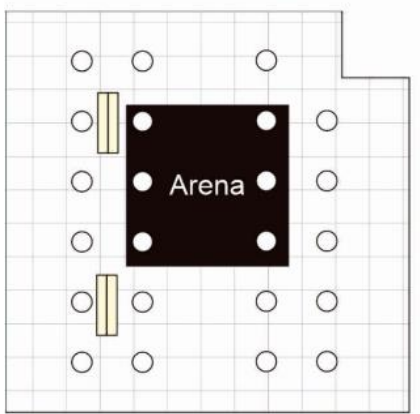

Dengan Lampu TL Kiri

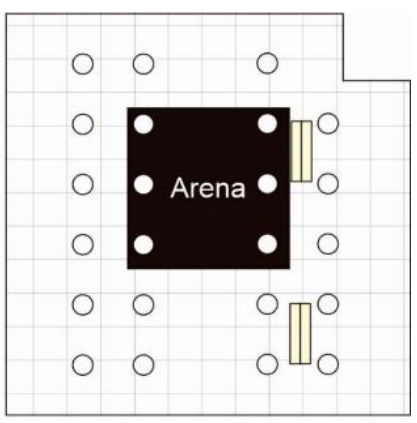

Dengan Lampu TL Kanan

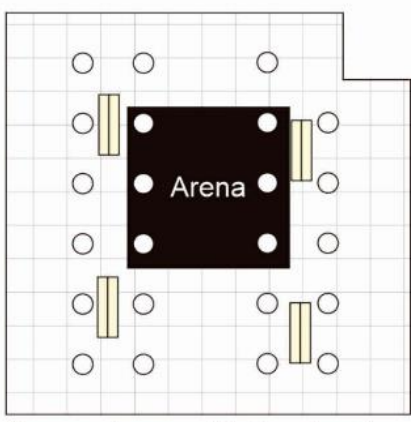

Dengan Lampu TL Keseluruhan
Gambar 10. Kondisi Pencahayaan Pengujian Tindakan Duckiebot.

Pengujian dilakukan dengan posisi-posisi yang sama seperti pada Gambar 6. Hasil pengujian yang didapat adalah sebagai berikut:

Tabel 4. Pengujian Dengan Traffic Light Kanan Posisi (a).

\begin{aligned} & \hline Pengujian ke \multicolumn{1}{c}{ Hasil Pengujian } \\ & \hline 1 Gagal \\ & \hline 2 Gagal \\ & 3 Gagal \\ & \hline 4 Gagal \\ & \hline 5 Gagal \\ & \hline\end{aligned}

Tabel 5. Pengujian Dengan Traffic Light Kanan Posisi (c)

\begin{aligned} & \hline Pengujian ke \multicolumn{1}{c}{ Hasil Pengujian } \\ & \hline 1 Berhasil \\ & \hline 2 Berhasil \\ & \hline 3 Berhasil \\ & \hline 4 Berhasil \\ & \hline 5 Berhasil \\ & \hline\end{aligned}

Tabel 6. Pengujian Dengan Traffic Light Kiri Posisi (a).

\begin{aligned} \hline Pengujian ke & \multicolumn{1}{c}{ Hasil Pengujian } \\ \hline 1 & Berhasil \\ \hline 2 & Berhasil \\ \hline 3 & Berhasil \\ \hline 4 & Gagal \\ \hline 5 & Berhasil \end{aligned}

Tabel 7. Pengujian Dengan Traffic Light Kiri Posisi (c).

\begin{aligned} & \hline Pengujian ke \multicolumn{1}{c}{ Hasil Pengujian } \\ & \hline 1 Gagal \\ & \hline 2 Gagal \\ & \hline 3 Gagal \\ & \hline 4 Gagal \\ & \hline 5 Gagal \\ & \hline\end{aligned}

Pada Tabel 4 dan Tabel 5 hasilnya berbanding terbalik dengan Tabel 6 dan Tabel 7. Kondisi pencahayaan mempengaruhi pembacaan warna traffic light. Saat pengujian traffic light kanan posisi (a) menjadi backlight, sebaliknya pada saat pengujian traffic light kiri posisi (c) yang menjadi backlight. Saat traffic light dinyalakan keseluruhan, hasilnya sama seperti kondisi pencahayaan awal. Hasil pengujian dengan traffic light keseluruhan terdapat pada Tabel 8 dan Tabel 9.

Tabel 8. Pengujian Dengan Traffic Light Keseluruhan Posisi (a).

\begin{aligned} & \hline \multicolumn{1}{c}{ Pengujian ke } \multicolumn{2}{c}{ Hasil Pengujian } \\ & \hline 1 Gagal \\ & \hline 2 Berhasil \\ & \hline 3 Gagal \\ & \hline 4 Gagal \\ & \hline 5 Berhasil \\ & \hline\end{aligned}

Tabel 9. Pengujian Dengan Traffic Light Keseluruhan Posisi (c).

\begin{aligned} & \hline Pengujian ke \multicolumn{1}{c}{ Hasil Pengujian } \\ & \hline 1 Berhasil \\ & \hline 2 Gagal \\ & \hline 3 Berhasil \\ & \hline 4 Berhasil \\ & \hline 5 Berhasil \\ & \hline\end{aligned}


E. Pengujian Tindakan Duckiebot terhadap Traffic Light Tertutup.

Pengujian tindakan Duckiebot terhadap traffic light tertutup dilakukan untuk mengetahui apakah Duckiebot dapat mendeteksi traffic light dengan keberadaan traffic light yang hanya terlihat sebagian saja atau tidak. Hasil pengujian saat traffic light tertutup, kamera masih dapat mendeteksi selama range warna terbaca. Hasil pengujian terdapat pada Gambar 11.
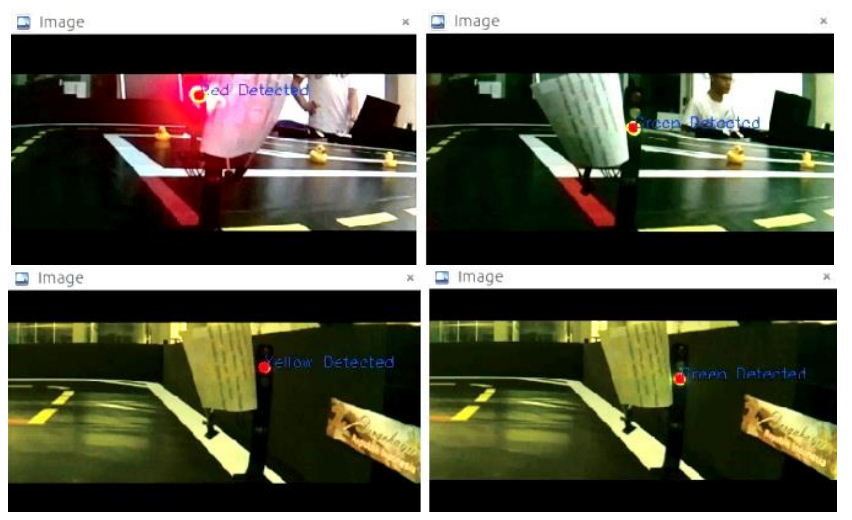

Gambar 11. Screenshot Pengujian Traffic Light Tertutup.

F. Pengujian Tindakan Duckiebot dengan adanya Spanduk.

Pengujian tindakan Duckiebot dengan adanya spanduk dilakukan dengan tujuan untuk mengetahui seberapa sensitifnya Duckiebot dalam mendeteksi traffic light dengan daerah sekitarnya. Hasilnya, Duckiebot tetap dapat mendeteksi traffic light dengan baik meskipun ada spanduk bahkan spanduk yang berwarna sama seperti traffic light. Hasil pengujian terdapat pada Gambar 12.

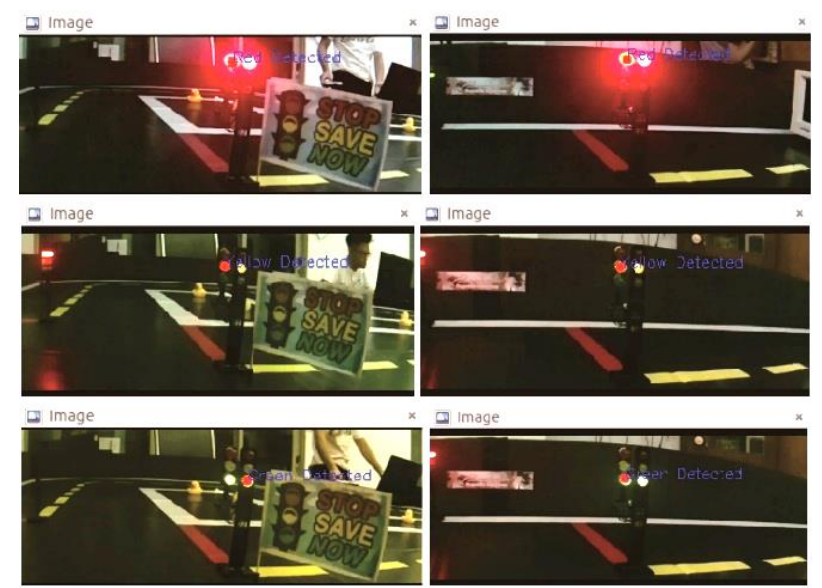

Gambar 12. Screenshot Pengujian Traffic Light Dengan Adanya Spanduk.

\section{KESIMPULAN}

Berdasarkan hasil penelitian ini, diperoleh beberapa kesimpulan diantaranya adalah sebagai berikut:

- Dari hasil pengujian Duckiebot saat lurus dari sebuah persimpangan, keberhasilan Duckiebot sebesar 70\% dalam mendeteksi dan bertindak sesuai terhadap traffic light yang ada. Selain itu, hasil pembacaan kamera tidak terpengaruh dengan adanya gambar-gambar spanduk yang serupa dengan traffic light.

- Kamera sensitif terhadap pencahayaan, sehingga diperlukan pencahayaan yang merata.

- Aturan dalam pembuatan arena Duckietown seperti bahan dan ukuran jalur berpengaruh terhadap jalannya Duckiebot saat mode lane following dijalankan.

\section{REFERENSI}

[1] Massachusetts Institute of Technology. (2016). What is Duckietown?". Diakses dari: http://duckietown.mit.edu/ pada tanggal 24 September 2017.

[2] Sudarono. (2011). Pengendalian Blok Sistem Traffic Light Dengan Pengaturan Rush Hour Yang Dapat Diatur Secara Terjadwal. Diakses dari: http://eprints.ums.ac.id $/ 12284 /$.

[3] Mu, G., Xinyu, Z., Deyi, L., Tianlei, Z. \& Lifeng, A. (2015). Traffic Light Detection And Recognition For Autonomous Vehicles. The Journal of China Universities of Posts and Telecommunications, 22(1), pp. 50-26. 